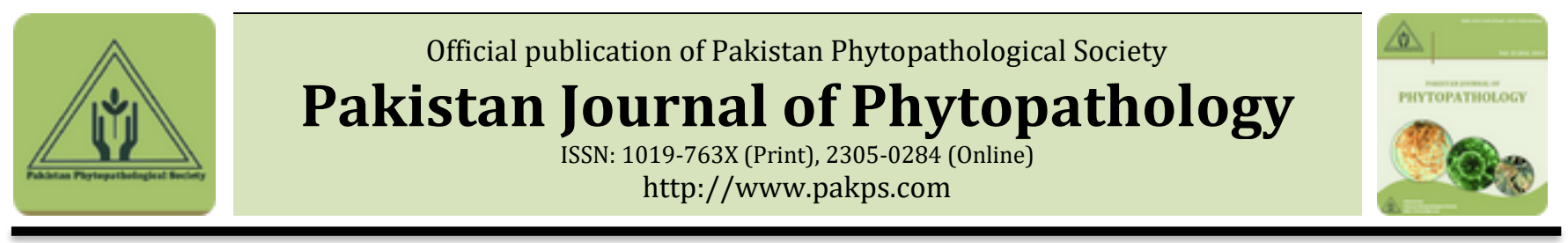

\title{
EFFICIENCY OF SOME PLANT EXTRACTS TO CONTROL OF PENICILLIUM ITALICUM WEHMER CAUSING BLUE MOLD ON LEMON FRUITS IN IRAQ
}

\author{
aAhed A. A. H. Matloob*, bHamid A. A. Khafaji \\ ${ }^{a}$ Al-Mussaib Technical college, Al-Furat Al-Awsat Technical University,51009, Iraq. \\ ${ }^{\boldsymbol{b}}$ Al-Mussaib Technical insititue, Al-Furat Al-Awsat Technical University,51009. Babylon, Iraq.
}

\begin{abstract}
A B S T R A C T
The study aimed to evaluate the efficacy of the water extract of Propolis, Wild mustard and dates vinegar in the inhibition of Penicillium italicum causal agent of Blue mold on a lemon fruits. The results showed that all tested extracts with concentrations 5, 10 and $15 \%$ had a high inhibitory effect against $P$. italicum. Dates vinegar is highly effective and showed $100 \%$ inhibition of P. italicum and protected lemon fruit from infection. First time this type of natural inhibitory water extracts are used in Iraq which resulted that the dates vinegar is the best suitable option for the management of lemon blue mold disease in post-harvest.
\end{abstract}

Keywords: lemon, Blue mold, plant extracts, disease, inhibition, propolis.

\section{INTRODUCTION}

Lemon, (Citrus limon L. Osbeck) is exposed to several post-harvest diseases caused by field and storage fungi. Infections of post-harvest diseases are directly related to the mechanical damage, wounds and abrasions during harvesting, packaging, transportation and storage. Blue mold disease is the most devastating post-harvest disease caused by the fungus Penicillium italicum (Agrios, 2005) This disease belongs to gardens, during refrigeration, storage and marketing, and the disease becomes more aggressive due to damp conditions. Green mold fungi on fruits exhibits the dark blue round areas with mature spores surrounded by white mycelia growth of $P$. italicum (Holmes and Eckert, 1999). Blue mold infected fruits are responsible for the new infection in healthy fruits. Humidity favors the disease development (Agrios, 2005). The losses of blue mold disease are estimated at 10-40\% (Wilson and Wisniewski, 1994; Yin et al, 2017). Several disease management options have been made, including chemical control (Obagwu and Korsten, 2003) such as

Submitted: September 20, 2018

Revised: December 31, 2018

Accepted for Publication: March 19, 2019

* Corresponding Author:

Email: ahad_20071980@yahoo.com

(C) 2017 Pak. J. Phytopathol. All rights reserved. thiabendazoie (TBZ, imazalil (IMZ) and ortho-phenil phenate, which are sprayed on fruits to reduce the effectiveness of pathogenic fungi and increase storage time. Use of hazardous chemicals is responsible for the increase in the human health and environmental risks and also leads to the pathogen resistance against the pesticide. There is a need to develop alternatives to fungicides to control post-harvest diseases, including biological control and the adoption of natural products, including seed powders, water extracts and alcohol for a many of the plants. Natural products are eco-friendly, cheap and conserve the losses by inhibiting the pathogen. Plant extracts are contain many active compounds that inhibit the growth of many plant pathogens (Singh and Sharma 1978; Chung et al., 2002; Al-Samarrai et al., 2013, Sattar etal,2014). This study aimed to evaluate the inhibitory activity of some water extract based natural products of propolis, wild mustard (Sinapis arvensis L.) and dates vinegar against P.italicum on the lemon fruits under natural storage conditions in the laboratory.

\section{MATERIALS AND METHODS}

Isolating the fungus $P$. italicum from the infected lemon fruits and diagnosis: Blue mold infected lemons were collected from the local markets of the province of Babylon, Iraq. The potato sucrose agar (PSA) medium 
was used for the isolation and purification of the blue mold fungus $P$. italicum from the diseased lemon fruits. The culture were incubated at $25 \pm 1^{\circ} \mathrm{C}$ for 2-3 days. The morphological studies were made under compound microscope to confirm the $P$. italicum (Pitt, 1988).

Pathogenicity testing of the P. italicum: P. italicum was isolated from the isolation process. The healthy and homogeneous fruits were selected in terms of maturity and size. As far as possible, the local lemon fruits were surface sterilized with a $1 \%$ concentration of sodium hypochlorite solution by immersing them for 3-5 minutes in Beaker 's capacity $1000 \mathrm{ml}$ and then lifted from the minor solution and rinsed with sterile water three times and dried on sterile filter paper. A wounds as (+) form $4 \mathrm{~cm}$ (length $\times$ wide) depth $2-5 \mathrm{~mm}$, or as longitudinal ligament was made of healthy fruits using sterile blades, re-sterilization with flame after each operation. The wounds inoculated with a 5 mm diameter of the P.italicum colony, incubated for 5 days in laboratory conditions at $25 \pm 1^{\circ} \mathrm{C}$ in containers of disposable cork.

Efficacy of propolis, wild mustard and vinegar on the growth of Penicillium italicum on the PSA: The water extract of the propolis was Prepared by taking $10 \mathrm{~g}$ of propolis (obtained from some of the beekeepers in Babylon governorate), cut small pieces and put in a $250 \mathrm{ml}$ glass flask and add $100 \mathrm{ml}$ sterilized distilled water and left for 5 days at room temperature with hand shaking from time to time to increase the solutes of propolis. The Propolis extract was prepared by solve $10 \mathrm{~g}$ of propolis, in $100 \mathrm{ml}$ of sterilized distilled water and left for 5 days at room temperature with hand shaking. The solution was applied with a clean, sterile cloth to dispose of the large particles and then use the Whatman No.1 filter paper placed in a funnel with a clean, sterilized glass flask. concentrate the entire filtrate from the extraction process in a $50 \mathrm{C}$ water bath to get rid of the water and obtained a thick liquid (Stock). The extracts were stored in glass bottles marked and sealed and placed in the refrigerator $\left(4^{\circ} \mathrm{C}\right)$ until use (Contari, 1987). As for the wild mustard seeds (obtained from local markets), they were crushed using an electric mallet, and the powder was placed in polythene bags, formed and stored in the refrigerator $\left(4^{\circ} \mathrm{C}\right)$. The extraction followed the similar method of a propolis above. The efficacy of the water extract of propolis, Wild mustard and vinegar against pathogenic fungus with $0,5,10,15 \%$ concentrates was tested by the food poisoning method (Dixit et al., 1976). After the hardening of the medium, the dishes were inoculated in the center with a diameter of 0.5 $\mathrm{cm}$ from the medium containing the growths of the fungus Penicillium italicum. At 5 day incubation of the dishes at 25 $+1^{\circ} \mathrm{C}$. The experiment was carried out according to the complete random design, and the results were obtained after the arrival of the fungal diameter of the comparative treatment to the edge of the dish by calculating the rate of measurement of two perpendicular diameter of the growth of each colony. The percentage of inhibition was calculated according to the following equation:

$$
\% \text { inhibition }=(\mathrm{R}-\mathrm{r} / \mathrm{R}) \times 100
$$

$\mathrm{R}=$ colony diameter comparison rate, $\mathrm{r}=$ colony diameter treatment rate.

Protection of lemon fruits from injury caused by blue mold under storage conditions: The fruits of the lemon were brought from the local market. The fruits of the infected, small and mechanically damaged were excluded. The fruits of the lemon were chlorinated (commercial bleach) at a concentration of $6 \%$ for 2-3 minutes. After that they were washed with distilled and sterilized water and left the fruits until their dryness. Wounds $(6-7 \mathrm{~cm}$ long, $0.5 \mathrm{~cm}$ depth) were made on fruits, the fruits of the lemon were treated with the extracted extracts using cotton soaked in the extract. The fruit was then treated several times. The fruit was then dried on the sterile filter leaves. The wounds were inoculated with a disk from the 7-day age of pathogen colony, with lemon fruits treated with only water used as a comparative treatment. The fruits were stored in cork containers prepared for this purpose. 3 fruits were used for each replicator and 3 replicates per treatment and left in the incubator at $25 \pm 1^{\circ} \mathrm{C}$ for 10 days. Follow the Complete randomized design (CRD) in the experiment. The percentage of infection According to the following Equation:

$$
\% \text { infection }=(\mathrm{I} / \mathrm{T}) \times 100
$$

$\mathrm{I}=$ number of infected fruits, $\mathrm{T}=$ total number of fruits examined

The severity of the disease was calculated according to the following disease index, $0=$ healthy fruits, $1=1-25 \%$ of the fruit area infected, $2=$ more than $25-50 \%$ of the fruit area is infected, $3=$ more than $50-75 \%$ of the fruit area infected, 4 $=$ more than $75-100 \%$ of the fruit area infected. The percentage of severity of injury was calculated according to the Mckinney equation (1923) as follows:

$$
\% \text { Inhibition }=\frac{(\text { Number of plants in the class } 0 \times 0)+(\text { Number of plants in class } 5 \times 5)}{\text { Total number of plants examined } \times 5} \times 100
$$




\section{RESULTS AND DISCUSSION}

Isolation of $P$. italicum fungus from the affected lemon fruits and its diagnosis: Three isolates of $P$. italicum were obtained from the affected lemon fruits. The colonies of all the isolates belonging to the $P$. italicum fungi were green-bluish, The mycelium was white, divided by septa. The conidiophores grow vertically and branch out from the top into several branches with large numbers of conidia spores, arranged in chains resembling a broom or brush. The spores were elongated and smooth.
Test of the pathogenic ability of the fungi P. italicum: The results showed that the isolate of P. italicum, of the affected lemons (Figure 1), was highly pathogenic to the healthy lemon fruits. The symptoms of the infection on healthy fruits was appearance after 3-4 Days of inoculation with $P$. italicum. The progressive development of white growth formation surrounded by water layer and then the formation of blue spores giving it the distinctive blue color of the disease and covered by the fruits in full and in the end shrinking, rotting and decomposition of the fruit.

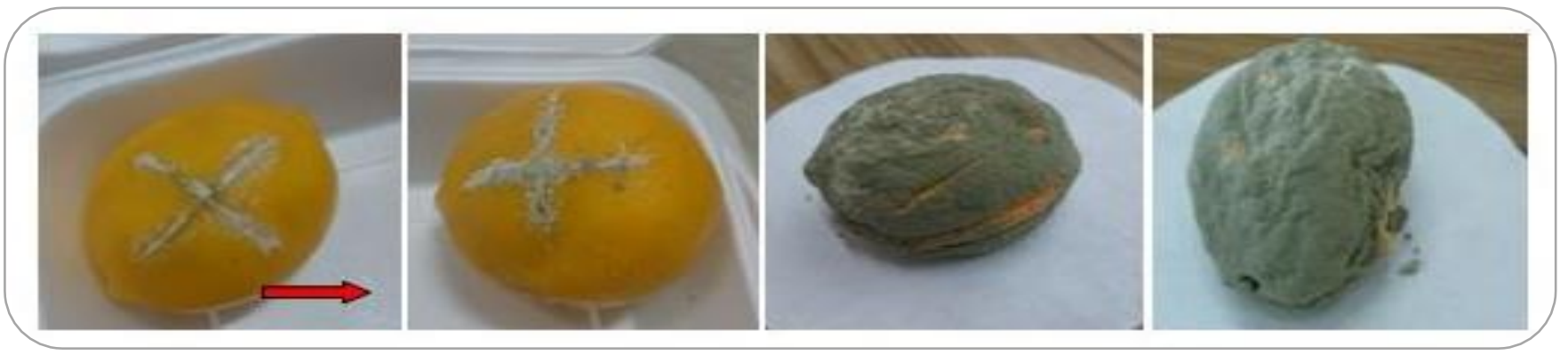

Figure 1. The experience of the Penicillium italicum on lemon fruits, the formation of Blue spores giving it the distinctive Blue color of the disease.

Effect of water extract of propolis, Wild mustard and date palm vinegar in the growth of Penicillium italicum on the PSA: The results as shown in (Table 1) represented that all tested extracts (Propolis, Wild mustard and Date palm vinegar) with concentrations 5, 10 and 15\% reduce the growth rates of P.italicum with significant difference comparison to pathogenic fungus alone. The treatment of date vinegar were superior into other treatments which prevented pathogen growth completely, the antagonistic ability of Wild mustard and propolis were significantly increased with concentration of $15 \%$ which were $88.90 \%$ and $81.03 \%$ respectively. The propolis efficiency may be due to its contains of many chemical compounds such as resinous substances, balsam, waxes, essential oils, flavones, elements, organic substances, etc. which against a large number of microorganisms (Kaal, 1991). This result was agreement with Doudi et al. (2016) the investigation revealed that many plant extracts were effective in the inhibition the mycelial growth and sporulation of of many pathogenic fungi such as Penicillium sp.

Table 1. Effect of the water extract of propolis, Wild mustard and date palm in the growth of Penicillium italicum on the PSA.

\begin{tabular}{lccc}
\hline Treatments* & Concentrates & Diameter of fungal growth $\backslash \mathrm{cm}^{2}$ & \% inhibition \\
\hline Pi+ propolis & 5 & 2.00 & 77.77 \\
& 10 & 1.47 & 83.67 \\
& 15 & 1.00 & 88.90 \\
Pi+ Wild mustard & 5 & 2.42 & 73.15 \\
& 10 & 2.07 & 77.03 \\
Pi+ Dates vinegar & 15 & 1.63 & 81.03 \\
& 5 & 0.00 & 100.00 \\
Control Pi. Alone & 10 & 0.00 & 100.00 \\
L.S.D. $(P<0.05)$ & 15 & 0.00 & 100.00 \\
\hline
\end{tabular}

*Each number represents the rate of three replicates, $\mathrm{Pi}=$ Penicillium italicum.

Effect of water extract of propolis, Wild mustard and date palm in the proportion and severity of fungus Penicillium italicum Cause of blue mold disease: The results showed in (Table 2) (Figure 2) that the aquatic extracts of propolis, Wild mustard, and date palm were decrease growth of $P$. italicum fungus and significantly 
improved in the treatment of date vinegar due to the inhibition of pathogenic fungi $100 \%$. The extract of Propolis showed inhibitory effect against the P.italicum and provided protection despite the growth of the fungus, compared to the treatment of fungus alone in which the fruits were covered with full fungal growth and the disease incidence and severity of infection was $100 \%$. The Wild mustard seed extract showed high efficacy against the fungus causing the disease and reduced the disease incidence and severity of the infection to 33.3 and $19.4 \%$, respectively. the effectiveness of Wild mustard extract may result from containing on chemical compounds which have a negative impact on the growth of pathogenic fungus, which led to change the properties of the natural crust and make the media less suitable for the growth of fungus, and these compounds is the chemical compound Glucosinolate as this compound there are high concentrations in the Cruciferous family plants when the hydrolysis of this compound by the enzyme Myrosinase produces many influential chemical compounds on pathogenic fungi, such as Azotheiossianat (Isothiocyantes) and cyanide ions and ions Aczasuldantiones Oxazolidinthiones Althaaossianat sulfide and carbonyl second oxide, The carbon and hydrogen sulfide and a number of alcoholic compounds

Table 2. Effect of propolis, Wild mustard and date vinegar in the proportion and severity of the fungus Penicillium italicum, causing blue mold on lemon fruits.

\begin{tabular}{ccc}
$\begin{array}{c}\text { Table 2. Effect of propolis, Wild mustard and date vinegar in the proportion and severity of the fungus Penicillium } \\
\text { italicum, causing blue mold on lemon fruits. }\end{array}$ & \%Disease incidence \\
\hline Treatments* & 22.1 & Disease severity\% \\
\hline Pi+propolis & 33.3 & 8.3 \\
Pi+ Wild mustard & 0 & 0.4 \\
Pi+ Dates vinegar & 100 & 100 \\
Control Pi. Alone & 0 & 0 \\
Control without pathogen & 15.6 & 7.8 \\
L.S.D. $(P<0.05)$ &
\end{tabular}

* Each number represents the rate of three replicates, $\mathrm{Pi}=$ Penicillium italicum.

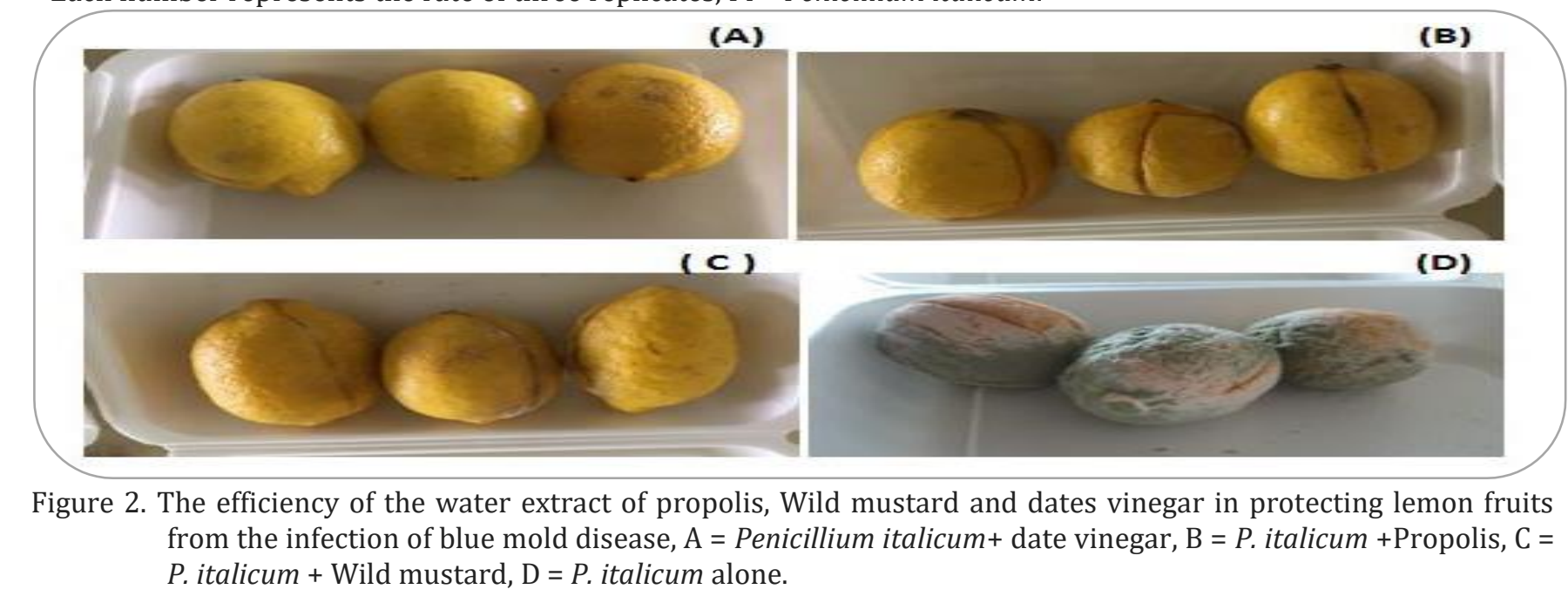

Figure 2. The efficiency of the water extract of propolis, Wild mustard and dates vinegar in protecting lemon fruits from the infection of blue mold disease, $\mathrm{A}=$ Penicillium italicum + date vinegar, $\mathrm{B}=$ P. italicum + Propolis, $\mathrm{C}=$ P. italicum + Wild mustard, $\mathrm{D}=$ P. italicum alone.
(Brown et al., 1991 and Mayton et al., 1996). propolis efficiency may be due to inhibition of many chemical compounds inhibiting a large number of harmful microorganisms (Kaal, 1991). This result was agreement with Jiratko (1994) found that the methyl and hydrolytic alcohol extract of the plant Impatiens balsamina inhibited the growth of P.italicum fungus causing blue mold in dishes. And agreement with Peng et al (2012) was concluded that pinocembrin isolated from propolis inhibited the mycelial growth of $P$. italicum by interfering energy homeostasis and cell membrane damage of the pathogen. The results are consistent with Vitoratos et al. (2013) the effective in several plant extracts against a number of pathogenic fungi, including P.italicum.

\section{CONCLUSIONS}

The conclusions of this study were that the presence of blue mold disease and spread in the local markets of the province of Babylon in the fruits of imported lemon, the fungus Penicillium italicum is the main cause of the disease of blue mold on the lemon. The efficiency of the water extract of Propolis, Wild mustard and date palm vinegar in inhibiting the growth of the P. italicum fungus on the PSA and providing good protection for the fruits from the pathogenic fungus. 


\section{REFERENCES}

Agrios, G. 2005. Plant diseases caused by viruses. Plant Pathology. Fifth Edition. Elsevier Academia Press: 724-820.

Al-Samarrai, G. F., H. Singh and M. Syarhabil. 2013. Extracts some plants on controlling green mold of orange and on postharvest quality parameters. World Applied Sciences Journal, Deira, 22: 564-570.

Brown, P. D., M. J. Morra, J. P. McCaffrey, D. L. Auld and L. Williams. 1991. Allelochemicals produced during glucosinolate degradation in soil. Journal of Chemical Ecology, 17: 2021-2034.

Chung, W. C., J. W. Huang, H. C. Huang and J. F. Jen. 2002. Effect of ground Brassica seed meal on control of Rhizoctonia damping-off of cabbage. Canadian Journal of Plant Pathology, 24: 211-218.

Contari, G. 1987. Process for the propolis extract preparation. Apicolt. Mod, 78: 147-150.

Dixit, S. N., S. C. Tripathi and R. R. Upadhyay. 1976. The antifungal substance of rose flowers(Rosa indica). Economic Botany, 30: 371-374.

Doudi, M., M. Setorki and Z. Rezayatmand. 2016. Effects of aqueous extract of Cinnamomum verum on growth of bread spoilage fungi. International Journal of Medical Research \& Health Sciences, 5: 162-171.

Holmes, G. J. and J. W. Eckert. 1999. Sensitivity of Penicillium digitatum and $P$. italicumto Postharvest Citrus Fungicides in California. Phytopathology, 89: 716-721.

Jiratko, J. 1994. Effect of plant extracts on blue mould of citrus fruit (Penicillium italicum Wehmer) and grey mould (Botrytis cinerea Pers.). Ochrana Rostlin, 30: 273-282.

Kaal, J., 1991, Natural Medicine from Honey Bees (Apitherapy), Kaal's Printing House, Amsterdam, Him. 8-21.
Mayton, H. S., C. Olivier, S. F. Vaughn and R. Loria. 1996. Correlation of fungicidal activity of Brassica species with allyl isothiocyanate production in macerated leaf tissue. Phytopathology, 86: 267271.

Obagwu, J. and L. Korsten. 2003. Integrated control of citrus green and blue molds using Bacillus subtilis in combination with sodium bicarbonate or hot water. Postharvest Biology and Technology, 28: 187-194.

Peng, L., S. Yang, Y. J. Cheng, F. Chen, S. Pan and G. Fan. 2012. Antifungal activity and action mode of pinocembrin from propolis against Penicillium italicum. Food Science and Biotechnology, 21: 1533-1539.

Pitt, J. I. 1988. A laboratory guide to common Penicillium species. CSI Res. Org. Div. Food Processing.

Sattar, A., A. Riaz, S. Ahmed and I. Hassan. 2014. Efficacy of selected plant extracts for inhibition of Penicillium expansum growth on apple fruits. Pakistan Journal of Phytopathology, 26: 63-66.

Singh, L. and M. Sharma. 1978. Antifungal properties of some plant extracts. Geobios, 5: 49-53.

Vitoratos, A., D. Bilalis, A. Karkanis and A. Efthimiadou. 2013. Antifungal Activity of Plant Essential Oils Against Botrytis cinerea, Penicillium italicum and Penicillium digitatum. Notulae Botanicae Horti Agrobotanici Cluj-Napoca, 41: 86.

Wilson, C. L. and M. E. Wisniewski. 1994. Biological control of postharvest diseases of fruits and vegetables: Theory and Practice. (CRC press: Floria).

Yin, G., Y. Zhang, K. Pennerman, G. Wu, S. Hua, J. Yu, W. Jurick, A. Guo and J. Bennett. 2017. Characterization of Blue Mold Penicillium Species Isolated from Stored Fruits Using Multiple Highly Conserved Loci. Journal of Fungi, 3: 12. 